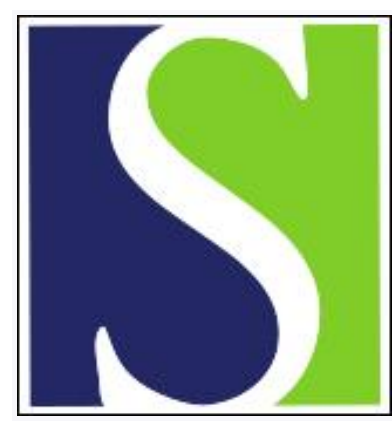

Scand J Work Environ Health 1991;17(2):104-109

https://doi.org/10.5271/sjweh.1727

Issue date: Apr 1991

\title{
Coxarthrosis and physical work load.
}

by Vingard E, Hogstedt C, Alfredsson L, Fellenius E, Goldie I, Koster M

Affiliation: Department of Occupational Medicine, Karolinska Hospital, Stockholm, Sweden.

The following article refers to this text: 2013;39(5):486-494

This article in PubMed: www.ncbi.nlm.nih.gov/pubmed/2047812 


\title{
Coxarthrosis and physical work load
}

\author{
by Eva Vingård, MD, ${ }^{1}$ Christer Hogstedt, MD, ${ }^{1,2}$ Lars Alfredsson, PhD, ${ }^{1}$ Evy Fellenius, $\mathrm{RN}^{2}$ \\ Ian Goldie, $\mathrm{MD}^{3}$ Max Köster, $\mathrm{BA}^{1}$
}

\begin{abstract}
VINGÅRD E, HOGSTEDT C, ALFREDSSON L, FELLENIUS E, GOLDIE I, KÖSTER M. Coxarthrosis and physical work load. Scand J Work Environ Health 1991;17:104-9. A case-referent study was performed on the possible relationship between physical work loads and an increased risk of developing coxarthrosis. The cases were 239 male recipients of a hip prosthesis as a result of severe idiopathic coxarthrosis; the referents were 302 men randomly selected from the general population. The work load was assessed through an interview and a self-administered questionnaire on the men's specific work periods. Men highly exposed to dynamic or static work loads had an increased relative risk of 2.42 (95 \% confidence interval 1.45-4.04) for developing coxarthrosis when compared with men with low exposure. Men with high exposure to heavy lifting between the ages of 30 and 49 years had the highest relative risk, 3.31 (95\% confidence interval 1.97-5.57). Long-time exposure to physical work loads seems to be a risk factor for severe coxarthrosis among men.
\end{abstract}

Key terms: dynamic work load, hip, lifting, occupation, osteoarthrosis, static work load.

Osteoarthrosis is the most common articular disorder affecting man. It can be divided into an idiopathic (or primary) form, for which a specific etiology has not yet been found, and a secondary form in which the process starts in a joint as a sequence of anatomic abnormality, trauma, or developmental or congenital disease $(1-5)$.

Investigations of coxarthrosis (ie, oseoarthritis of the hip joint) and occupational physical work load are rare. Only investigations concerning occupational groups, not individual assessments of physical work load, have been performed. Coxarthrosis has been found to be more common among farmers than among reference groups in studies from France (6), Sweden (7), and Finland (8). Lindberg and his co-workers (9) found a higher but not statistically significant excess of coxarthrosis when investigating the prevalence of coxarthrosis among blue-collar shipyard workers using a random sample of men from the general population in the same region as a reference group. In a cohort study from Sweden (10) different blue-collar occupations were classified as highly or lowly exposed to forces acting on the hip, and the frequencies of the outcomes were compared. Male farmers, construction workers, firefighters, and some food processing workers were shown to have an excess risk of hospitalization due to osteoarthrosis of the hip.

\footnotetext{
1 Department of Occupational Medicine, Karolinska Hospital, Stockholm, Sweden.

2 Division of Occupational Health, National Institute of Occupational Health, Solna, Sweden.

3 Department of Orthopaedics, Karolinska Hospital, Stockholm, Sweden.
}

Reprint requests to: Dr E Vingård, Department of Occupational Medicine, Karolinska Hospital, S-104 01 Stockholm, Sweden.
Experimental studies on animals have shown that compression of a joint, especially in extreme positions, with or without oscillating and repetitive impulsive load, increases the osteoarthrotic changes in exposed joints $(11-14)$. From these studies and epidemiologic investigations of some athletes $(15-16)$, it is possible to suggest the following two major hypotheses concerning the contribution of physical load to the osteoarthrotic process: (ii) dynamic forces from instant stress on the joint may result in microfractures of the cartilage and subchondral bone when the shock-absorbing capacity is exceeded and (ii) static compression hampers the movements of the joint and results in difficulties to eliminate metabolites and receive nourishment as the cartilage has neither blood vessels nor lymphatic drainage.

The objective of this case-referent study was to investigate whether long-term exposure to specific work postures and loads increases the risk of developing coxarthrosis.

\section{Subjects and methods}

\section{Subjects}

The study population comprised all Swedish men who were between the ages of 50 and 70 years and lived in the referral areas of four large hospitals in Stockholm. Information was collected from October 1984 to June 1988. The cases were those men in the study population who received a first-time prosthesis of the hip joint as a result of idiopathic osteoarthrosis. The orthopedic clinics involved were contacted each week; they delivered the names and addresses of new patients. The referents were randomly selected from the study population on four different occasions during the study period. Men in both groups with malformations, sequelae 
Table 1. Distribution of the cases and referents by age, their educational background, and their smoking habits.

\begin{tabular}{|c|c|c|c|c|c|c|c|c|c|c|c|c|c|c|}
\hline & \multicolumn{4}{|c|}{ Age group } & \multicolumn{6}{|c|}{ Educational backgrounda } & \multicolumn{4}{|c|}{ Smoking habits } \\
\hline & \multicolumn{2}{|c|}{$\begin{array}{c}50-59 \\
\text { years }\end{array}$} & \multicolumn{2}{|c|}{$\begin{array}{c}60-70 \\
\text { years }\end{array}$} & \multicolumn{2}{|c|}{$\begin{array}{l}\text { Elementary } \\
\text { school }\end{array}$} & \multicolumn{2}{|c|}{$\begin{array}{c}\text { Secondary } \\
\text { school }\end{array}$} & \multicolumn{2}{|c|}{ University } & \multirow{2}{*}{$\begin{array}{c}\text { No } \\
\text { infor- } \\
\text { mation } \\
(\%)\end{array}$} & \multirow{2}{*}{$\begin{array}{c}\text { Non- } \\
\text { smokers } \\
(\%)\end{array}$} & \multirow{2}{*}{$\begin{array}{c}\text { Ex- } \\
\text { smokers } \\
(\%)\end{array}$} & \multirow{2}{*}{$\begin{array}{c}\text { Smok- } \\
\text { ers } \\
(\%)\end{array}$} \\
\hline & $\mathrm{N}$ & $\%$ & $\mathrm{~N}$ & $\%$ & $\begin{array}{c}50-59 \\
\text { years } \\
(\%)\end{array}$ & $\begin{array}{c}60-70 \\
\text { years } \\
(\%)\end{array}$ & $\begin{array}{c}50-59 \\
\text { years } \\
(\%)\end{array}$ & $\begin{array}{c}60-70 \\
\text { years } \\
(\%)\end{array}$ & $\begin{array}{c}50-59 \\
\text { years } \\
(\%)\end{array}$ & $\begin{array}{c}60-70 \\
\text { years } \\
(\%)\end{array}$ & & & & \\
\hline $\begin{array}{l}\text { Cases } \\
\text { Referents }\end{array}$ & $\begin{array}{l}53 \\
75\end{array}$ & $\begin{array}{l}21 \\
23\end{array}$ & $\begin{array}{l}194 \\
247\end{array}$ & $\begin{array}{l}79 \\
77\end{array}$ & $\begin{array}{l}38 \\
34\end{array}$ & $\begin{array}{l}45 \\
38\end{array}$ & $\begin{array}{l}48 \\
50\end{array}$ & $\begin{array}{l}45 \\
47\end{array}$ & $\begin{array}{l}14 \\
16\end{array}$ & $\begin{array}{l}10 \\
15\end{array}$ & 1 & $\begin{array}{l}36 \\
34\end{array}$ & $\begin{array}{l}36 \\
38\end{array}$ & $\begin{array}{l}27 \\
28\end{array}$ \\
\hline
\end{tabular}

a Given by age group.

after poliomyelitis, rickets, or trauma to the trunk or lower extremities were excluded. Information regarding the occurrence of these disorders was obtained from the files of the hospital or through personal interviews.

An introductory letter was sent to all the subjects. A few days later they were contacted by telephone. Those interested in participating were interviewed about health status, smoking habits, education, sports activities, and occupational career. Information was also obtained about weight and height.

On the basis of information obtained in the telephone interview, each subjects' occupational career was divided into different periods with similar work tasks. For each such period the study participants were asked to complete a questionnaire about the specific physical work load in that type of work. The questionnaires were sent to the homes of the participants, and reminders followed after three, and then another two, weeks if the questionnaires were not returned.

The contacts with the hospitals, the telephone calls, and the interviews were performed by the same nurse during the entire investigation.

Men who undergo surgery and are on sick leave may recall exposure more thoroughly than men from the general population, many of whom are still working. To investigate this possible recall bias, we also interviewed patients who were treated for a first episode of myocardial infarction in the same hospitals as the coxarthrosis cases. The same procedures were used.

The case group consisted of 253 men. Five could not be reached by telephone, one did not want to participate, and 14 did not return their questionnaires but answered the questions in the telephone interview. Therefore 233 cases $(92 \%)$ participated in the whole study and $247(98 \%)$ in parts of the study. Thirty-eight percent had bilateral coxarthrosis.

The reference group consisted of 392 men. Thirtyeight could not be reached by telephone, 32 did not want to participate, and 20 did not return their questionnaires but answered the questions in the telephone interview. Therefore 302 referents $(77 \%)$ participated in the whole study and $322(82 \%)$ in parts of the study. The myocardial infarction group comprised 345 men. Five of them could not be reached by telephone, and five did not want to participate.

The age distribution, educational level, and smoking habits were very similar for the cases and the refer-
Table 2. Self-reported medically treated hypertension and diabetes among cases and referents in different age groups.

\begin{tabular}{lccccc}
\hline & \multicolumn{2}{c}{ Hypertension } & & \multicolumn{2}{c}{ Diabetes } \\
\cline { 2 - 3 } \cline { 6 - 7 } & $\begin{array}{c}50-59 \\
\text { years } \\
(\%)\end{array}$ & $\begin{array}{c}60-70 \\
\text { years } \\
(\%)\end{array}$ & & $\begin{array}{c}50-59 \\
\text { years } \\
(\%)\end{array}$ & $\begin{array}{c}60-70 \\
\text { years } \\
(\%)\end{array}$ \\
\cline { 2 - 3 } Cases & 19 & 16 & & 3 & 8 \\
Referents & 7 & 21 & & 2 & 4 \\
\hline
\end{tabular}

ents (table 1). Treated hypertension was more common among the cases in the 50- to 59-year age group. Diabetes mellitus was equally distributed (table 2 ).

\section{Exposure classification}

In the questionnaires the study subjects were asked how many hours per week were spent in different work positions (eg, standing, sitting, walking, biking, and stair climbing); how many hours per week were spent driving a vehicle; how many hours per week were spent in a twisted position; and how many kilograms were lifted per week. Some other related questions were also asked.

Biomechanical investigations of hip-joint load have been performed under laboratory conditions but not in relation to specific job tasks. The available figures are shown in table 3. Everyday activities like sitting, walking without burdens, standing, and biking were classified as normal. Walking with burdens and stair climbing were classified as dynamic exposure, and working in a twisted locked position was classified as static exposure. These work tasks were quantified in hours per week.

The number of lifted kilograms, the number of times the person lifted heavy burdens $(>40 \mathrm{~kg}$ ), and the number of jumps between different levels are other ways of quantifying dynamic exposure. This information was analyzed separately.

Information regarding exposure was collected from the start of the occupational career to the year of the diagnosis for the cases and to the year of the interview for the referents. Exposure was then aggregated for the men's worklife up to 49 years of age. In an attempt to determine whether there were any differences between the loads affecting the joint in earlier versus later years, another aggregation into two periods was per- 
Table 3. Biomechanic measurements of forces acting on the hip joint in different postures.

\begin{tabular}{lll}
\hline Reference & Position & Force \\
\hline Frankel \& Nordin (17) & Standing (relaxed with no muscular force) & $0.33 \cdot$ body weight \\
Inman (18) & Standing on one leg & $2.4-2.6 \cdot$ body weight \\
Rydell $(19,20)$ & Walking & $1.6-3.3 \cdot$ body weight \\
Paul $(21)$ & Walking & $2.3-5.8 \cdot$ body weight \\
Seireg \& Arvikar (22) & Walking & $5.4 \cdot$ body weight (maximum) \\
Crowninshield (23) & Walking & $3.3-5.0 \cdot$ body weight \\
Paul (21) & Fast walking & $7.0 \cdot$ body weight (maximum) \\
Crowninshield (23) & Stair climbing & $5.0-7.0 \cdot$ body weight \\
Németh (24) & Lifting 12.5 kg & $2.6-3.2 \cdot$ body weight \\
Ericsson (25) & Biking & Less than walking \\
\hline
\end{tabular}

Table 4. Ranges of the different work-load exposures during the different age periods.

\begin{tabular}{|c|c|c|c|c|c|c|}
\hline Level of exposure & $\begin{array}{l}\text { Static }+ \\
\text { dynamic } \\
\text { (h) }\end{array}$ & $\begin{array}{l}\text { Only static } \\
\text { (h) }\end{array}$ & $\begin{array}{l}\text { Only dynamic } \\
\text { (h) }\end{array}$ & Lifted tons & $\begin{array}{l}\text { Number of } \\
\text { lifts of }>40 \mathrm{~kg}\end{array}$ & $\begin{array}{l}\text { Number of } \\
\text { jumps }\end{array}$ \\
\hline \multicolumn{7}{|l|}{ Low } \\
\hline $\begin{array}{l}\leq 29 \text { years } \\
30-49 \text { years } \\
\leq 49 \text { years }\end{array}$ & $\begin{array}{lr}0- & 999 \\
0- & 1238 \\
0- & 1499\end{array}$ & $\begin{array}{lr}0- & 480 \\
0- & 576 \\
0- & 1174\end{array}$ & $\begin{array}{lr}0- & 719 \\
0- & 999 \\
0- & 1151\end{array}$ & $\begin{array}{lr}0- & 74 \\
0- & 66 \\
0- & 137\end{array}$ & $\begin{array}{lr}0- & 999 \\
0- & 750 \\
0- & 1187\end{array}$ & $\begin{array}{lr}0- & 840 \\
0- & 450 \\
0- & 1019\end{array}$ \\
\hline \multicolumn{7}{|l|}{ Medium } \\
\hline $\begin{array}{l}\leq 29 \text { years } \\
30-49 \text { years } \\
\leq 49 \text { years }\end{array}$ & $\begin{array}{l}1000-9674 \\
1239-10264 \\
1500-17659\end{array}$ & $\begin{array}{r}481-4311 \\
577-6067 \\
1175-16079\end{array}$ & $\begin{array}{r}720-6999 \\
1000-7294 \\
1152-15909\end{array}$ & $\begin{array}{r}75-1699 \\
67-1247 \\
138-3006\end{array}$ & $\begin{array}{r}1000-16463 \\
751-17640 \\
1188-25199\end{array}$ & $\begin{array}{r}841-3999 \\
451-8084 \\
1020-7919\end{array}$ \\
\hline \multicolumn{7}{|l|}{ High } \\
\hline $\begin{array}{l}\leq 29 \text { years } \\
30-49 \text { years } \\
\leq 49 \text { years }\end{array}$ & $\begin{array}{r}9675-49788 \\
10265-50880 \\
17660-95868\end{array}$ & $\begin{array}{r}4312-32220 \\
6068-49776 \\
16080-76032\end{array}$ & $\begin{array}{r}7000-34425 \\
7295-36965 \\
15910-59880\end{array}$ & $\begin{array}{l}1700-45546 \\
1248-60000 \\
3007-94003\end{array}$ & $\begin{array}{l}16464-480000 \\
17641-772800 \\
25200-930600\end{array}$ & $\begin{array}{l}4000-16920 \\
8085-25200 \\
7920-38880\end{array}$ \\
\hline
\end{tabular}

formed. The two periods were $\leq 29$ years of age and $30-49$ years of age.

The men were classified by exposure to dynamic and static forces. Three exposure groups were defined on the basis of the loads in the reference group. Those unexposed and the $5 \%$ less exposed were considered to have low exposure. The rest of the exposed group was divided into two equally large groups, classified as the medium-exposure group and the high-exposure group (table 4).

\section{Information on potential confounding factors}

In an evaluation of the extent to which the association between physical work load and coxarthrosis was influenced by other factors, a stratified analysis was performed. In this analysis, age was categorized into three groups (49-59, 60-64, and 65-70 years) and smoking habits into two groups (current smokers and nonsmokers).

The men's sports activities were well documented. The cases and referents reported how many hours they had performed different sports during different age periods. The exposure from sports activities was quantified as low, medium, and high for each sport activity and for the total amount of hours in sports in the same way as for exposure from work load. Sports activities were more common in the earlier years, and the analyses were stratified according to the total hours of sports activities up to 29 years of age in the three different exposure classes of low, medium, and high. Body mass index was calculated for each person in the study, and the analysis was made with the subjects stratified into three groups, those with a low, normal, and high body mass index. The relationship between sports activities and coxarthrosis will be reported separately, as will the relationship between the body mass index and coxarthrosis.

\section{Statistical methods}

The incidence density ratios (relative risks) were estimated from the odds ratios. Potential confounding from age, body mass index, smoking habits, and sports activities were controlled through stratified analysis with the use of the method proposed by Mantel \& Haenszel (26). Ninety-five percent confidence intervals were calculated for the relative risks by the test-based method (27).

\section{Results}

The relative risks of developing severe coxarthrosis associated with different work loads in different age periods are shown in tables 5 and 6 . Men with high exposures until the age of 49 years had an adjusted relative risk of 2.42 [ $95 \%$ confidence interval $(95 \% \mathrm{CI})$ 1.45-4.04] for developing coxarthrosis in a compar- 
ison with the men with low exposure. The corresponding relative risk for those with medium exposure was $1.82(95 \%$ CI 1.02-3.24). When the different exposure periods were compared, those exposed between $30-49$ years of age had the highest relative risks. Dynamic exposure seems to give the highest pressure on the hip joint according to the biomechanical model. The total number of lifted tons during life might be a measurement of the dynamic pressure. The relative risk for those with high exposure up to the age of 49 years was 1.84 (95\% CI 1.12-3.03), and for those with medium exposure it was $1.58(95 \% \mathrm{CI} 0.93-$ 2.66). The subgroup with the highest dynamic load was probably that with frequent exposure to the lifting of burdens over $40 \mathrm{~kg}$. The relative risk for the men with high exposure in the period between 30 and 49 years of age was 3.31 (95\% CI 1.97-5.57).

\section{Discussion}

Mechanical stress may contribute to the multifactorial etiology of coxarthrosis. This study demonstrated an increased risk of developing severe coxarthrosis for those with medium and high exposure to physical work loads.

\section{Selection bias}

The men with coxarthrosis in this study had undergone surgery and were still on sick leave, while many of the referents were working. Only one person in the case group did not want to collaborate. The corresponding number for the reference group was $32(8 \%)$. Lack of time was the most common explanation for refusal to participate. For those who did not return their questionnaires, the occupational history was known, and it did not differ substantially from those of the men participating in the whole study.

A selection bias might have occurred if persons in certain occupations had moved to another geographic area after receiving their diagnosis of coxarthrosis (eg, for better availability to surgery). All health care, including surgery, is free of charge in Sweden, and everyone living in a certain geographic area in Stockholm is referred to a specific hospital. There was only one private hospital in Stockholm performing hip prothesis surgery during this period, and very few men used that expensive possibility.

Another selection bias could have appeared if men in heavy jobs received surgery earlier than men in sedentary jobs. In this study, the subjects were divided into three age groups. The relative risks were somewhat higher in the middle age group (60-64 years of age) and about the same in the youngest and oldest age groups. None of the three groups had an underrisk, which might have been expected in the oldest age group if the true relative risk is assumed to be equal to one. In a cohort study comparing blue-collar workers in heavy and sedentary jobs in Sweden (10), the
Table 5. Relative risk $^{a}$ (RR) and $95 \%$ confidence interval $(95 \% \mathrm{Cl})$ for developing coxarthrosis from medium or high exposure before the age of $\mathbf{4 9}$ years as compared with low exposure of different types.

\begin{tabular}{llllll}
\hline \multirow{2}{*}{ Exposure } & \multicolumn{2}{c}{$\begin{array}{c}\text { Medium } \\
\text { exposure }\end{array}$} & & \multicolumn{2}{c}{$\begin{array}{c}\text { High } \\
\text { exposure }\end{array}$} \\
\cline { 2 - 3 } \cline { 6 - 7 } & RR & $95 \% \mathrm{Cl}$ & & RR & $95 \% \mathrm{Cl}$ \\
\hline Static + dynamic & 1.82 & $1.02-3.24$ & & 2.42 & $1.45-4.04$ \\
Only static & 1.21 & $0.64-2.31$ & & 2.92 & $1.69-5.05$ \\
Only dynamic & 1.92 & $1.11-3.32$ & & 2.17 & $1.27-3.73$ \\
Lifted tons & 1.58 & $0.93-2.66$ & & 1.84 & $1.12-3.03$ \\
Number of lifts $(>40 \mathrm{~kg})$ & 1.38 & $0.81-2.36$ & & 2.40 & $1.50-3.83$ \\
Number of jumps & 1.83 & $\mathbf{1 . 0 6 - 3 . 1 4}$ & & $\mathbf{1 . 5 2}$ & $\mathbf{0 . 9 1 - 2 . 5 3}$ \\
\hline
\end{tabular}

a Relative risks adjusted for age, body mass index, smoking, and sports activities up to the age of 29 years.

Table 6. Relative risk ${ }^{a}$ (RA) and the $95 \%$ confidence interval $(95 \% \mathrm{Cl}$ ) for developing coxarthrosis from medium or high exposure of different types during the age period of $\leq 29$ years and $30-49$ years as compared with low exposure during the same age periods.

\begin{tabular}{|c|c|c|c|c|}
\hline \multirow{2}{*}{ Exposure } & \multicolumn{2}{|c|}{$\begin{array}{l}\text { Medium } \\
\text { exposure }\end{array}$} & \multicolumn{2}{|c|}{$\begin{array}{c}\text { High } \\
\text { exposure }\end{array}$} \\
\hline & RR & $95 \% \mathrm{Cl}$ & RR & $95 \% \mathrm{Cl}$ \\
\hline \multicolumn{5}{|l|}{ Static + dynamic } \\
\hline $\begin{array}{r}\leq 29 \text { years } \\
30-49 \text { years }\end{array}$ & $\begin{array}{l}1.74 \\
2.25\end{array}$ & $\begin{array}{l}1.06-2.87 \\
1.35-3.76\end{array}$ & $\begin{array}{l}1.97 \\
2.87\end{array}$ & $\begin{array}{l}1.22-3.18 \\
1.79-4.62\end{array}$ \\
\hline \multicolumn{5}{|l|}{ Only static } \\
\hline $\begin{array}{r}\leq 29 \text { years } \\
30-49 \text { years }\end{array}$ & $\begin{array}{l}1.91 \\
1.13\end{array}$ & $\begin{array}{l}1.06-3.44 \\
0.68-1.86\end{array}$ & $\begin{array}{l}2.29 \\
2.12\end{array}$ & $\begin{array}{l}1.38-3.81 \\
1.32-3.41\end{array}$ \\
\hline \multicolumn{5}{|l|}{ Only dynamic } \\
\hline $\begin{array}{r}\leq 29 \text { years } \\
30-49 \text { years }\end{array}$ & $\begin{array}{l}2.09 \\
1.50\end{array}$ & $\begin{array}{l}1.27-3.48 \\
0.90-2.49\end{array}$ & $\begin{array}{l}1.83 \\
2.36\end{array}$ & $\begin{array}{l}1.09-3.06 \\
1.46-3.82\end{array}$ \\
\hline \multicolumn{5}{|l|}{ Lifted tons } \\
\hline $\begin{array}{r}\leq 29 \text { years } \\
30-49 \text { years }\end{array}$ & $\begin{array}{l}1.73 \\
1.63\end{array}$ & $\begin{array}{l}1.06-2.83 \\
0.98-2.73\end{array}$ & $\begin{array}{l}1.95 \\
2.74\end{array}$ & $\begin{array}{l}1.23-3.09 \\
1.70-4.43\end{array}$ \\
\hline \multicolumn{5}{|c|}{ Number of lifts $(>40 \mathrm{~kg})$} \\
\hline $\begin{array}{r}\leq 29 \text { years } \\
30-49 \text { years }\end{array}$ & $\begin{array}{l}1.73 \\
1.60\end{array}$ & $\begin{array}{l}1.06-2.82 \\
0.81-3.15\end{array}$ & $\begin{array}{l}2.35 \\
3.31\end{array}$ & $\begin{array}{l}1.47-3.74 \\
1.97-5.57\end{array}$ \\
\hline \multicolumn{5}{|l|}{ Number of jumps } \\
\hline $\begin{array}{r}\leq 29 \text { years } \\
30-49 \text { years }\end{array}$ & $\begin{array}{l}1.80 \\
1.92 \\
\end{array}$ & $\begin{array}{l}1.06-3.04 \\
1.07-3.46\end{array}$ & $\begin{array}{l}1.39 \\
1.38\end{array}$ & $\begin{array}{l}0.85-2.26 \\
0.77-2.46\end{array}$ \\
\hline
\end{tabular}

a Relative risks adjusted for age, body mass index, smoking, and sports activities up to the age of 29 years.

relative risk for hospitalization due to coxarthrosis was more elevated for persons born in 1905-1924 (ie, most of them retired) than for those born in 1925-1945. These results contradict a job-selective indication for surgery in Sweden.

The potential selective forces were limited and probably did not cause any substantial underestimation or overestimation of the risks.

\section{Misclassification}

Only persons with coxarthrosis severe enough to warrant a hip prosthesis were included as cases in this study. Patients were excluded if any evidence of secondary osteoarthrosis was gathered in the interview or medical records. The borderline between idiopathic and secondary coxarthrosis is diffuse, and a nondifferential misclassification of diagnosis might have occurred. 
The interviewing nurse normally had contact with all the participating wards at the four hospitals every week, and therefore it is assumed that there were extremely few missing cases of coxarthrosis.

Exposure information was obtained from self-administered questionnaires, specified for each period with similar work tasks, from the beginning of the occupational career to the day of the interview or diagnosis. Each participant completed one to eight forms. A differential bias could have been introduced if the cases had recalled exposures more thoroughly than the referents. However, the amount of time that elapses between the exposure and the recall is probably a more important indicator of the accuracy of recall. In this study similar exposure interviews were made for men who had had a first myocardial infarction and were supposed to recall exposure very thoroughly too. The differences in self-reported physical work load between the men with myocardial infarction and the men from the general population were very small. The relative risk of hospitalization due to a myocardial infarction for men with medium exposure of both dynamic and static character was 1.05 (95\% CI $0.69-1.60)$, and for those with high exposure it was 1.24 (95\% CI $0.82-1.87$ ), when the comparison involved men with low exposure.

It is obviously very difficult to remember physical work loads with precision, especially many years after exposure. The information used in this study was the physical load until 49 years of age. Nondifferential misclassification due to memory deficiencies might have occurred that diminished the relative risk estimate towards unity in the high-exposure groups.

High exposure before the age of 30 years was associated with slightly lower risks than between $30-49$ years of age. When the effect of high exposure between $30-49$ years of age was analyzed, confounding from both high, medium, and low exposure before the age of 30 years was controlled for and vice versa. This procedure did not substantially change the relative risks. It seems biologically possible that at younger ages the hips could be better protected from bone and cartilage damage by strong muscles than later in life. Another explanation could be that nondifferential misclassification is more pronounced in the most distant time period.

Exposure from everyday activities like sitting, walking, standing, and biking was not considered as special exposure and was not analyzed. Sustained sitting or standing could be a static exposure, but, with our retrospective approach, it was impossible to divide between "normal" sitting and standing and more fixed static positions that could be harmful to the joint. Some persons, now classified as having low exposure, probably in this respect had medium or high static loads, and the impact on the relative risks depends on whether or not the misclassified persons belonged to the case or reference group.

\section{Confounding factors}

Age, body mass index, smoking habits, and sports activities were considered potential confounding factors and were controlled for in the analyses. No substantial confounding was indicated in any of the analyzed relationships. Present knowledge indicates that there is no reason to consider other factors for potential confounding.

\section{Concluding remarks}

Long-time exposure of men to both static and dynamic physical work loads seems to be a risk factor for clinically severe coxarthrosis.

\section{Acknowledgments}

This study was supported by grants from The National Institute of Occupational Health, Solna, Sweden, and The Swedish Work Environment Fund (88/1253).

We are grateful for the generous cooperation of the hospital wards.

\section{References}

1. Radin EL. Mechanical aspects of osteoarthritis. Bull Rheum Dis 1976;26:862-5.

2. Anderson JAD. Arthrosis and its relation to work. Scand J Work Environ Health 1984;10:429-33.

3. Felson D. Epidemiology of hip and knee osteoarthritis. Epidemiol Rev 1988;10:1-28.

4. Kelsey J. Epidemiology of musculoskeletal disorders. Oxford: Oxford University Press, 1982. (Monographs in epidemiology and biostatistics; vol 3).

5. Lawrence JS. Rheumatism in populations. London: William Heinemann Medical Books Ltd, 1977.

6. Pommier L. Contribution à l'étude de la coxarthrose chez l'agriculteur. Profil clinique et étiologique. A propos de 245 dossiers de coxarthrose chirurgical [Doctoral dissertation]. Tours (France): L'Université de Tours, 1977.

7. Axmacher B. Coxarthrosis in farmers as appearing in colon radiograms and urograms. In: Hogstedt $C$, Reuterwall $\mathrm{C}$, ed. Progress in occupational epidemiology. Amsterdam: Elsevier, 1988:203-6.

8. Typpo T. Osteoarthritis of the hip: radiological findings and etiology. Ann Chir Gynaecol 1985;74:5- 38.

9. Lindberg $\mathrm{H}$, Danielsson $\mathrm{L}$. The relation between labor and coxarthrosis. Clin Orthop 1984;191:159-61.

10. Vingård E, Alfredsson L, Goldie I, Hogstedt C. Yrke och arthros i höft och knä [Occupation and osteoarthrosis of the hip and knee]. Läkartidningen (in press).

11. Salter R, Field P. The effects of continuous compression on living articular cartilage. J Bone Joint Surg 1960;1:31-49.

12. Langenskiöld A, Michelsson J-E, Videman T. Osteoarthritis of the knee in the rabbit produced by immobilization. Acta Orthop Scand 1979;50:1-14.

13. Videman T. Experimental osteoarthritis in the rabbit. Acta Orthop Scand 1982;53:339-47.

14. Videman T. The effect of running on osteoarthritic joint: an experimental matched-pair study with rabbits. Rheumatol Rehabil 1982;1:1-8.

15. Klunder KB, Rud B, Hansen J. Osteoarthritis of the hip and knee joint in retired football players. Acta Orthop Scand 1980;51:925-7.

16. Marti B, Knobloch M, Tschopp A, Jucker A, Howald $\mathrm{H}$. Is excessive running predictive of degenerative hip 
disease? Controlled study of former elite athletes. $\mathrm{Br}$ Med J 1989;299:91-3.

17. Frankel V, Nordin M. Basic biomechanics of the skeletal system. Philadelphia, PA: Lea \& Febiger, 1980.

18. Inman VT. Functional aspects of the abductor muscles of the hip. J Bone Joint Surg 1947;29:607-19.

19. Rydell N. Forces acting on the femoral head prothesis. Acta Orthop Scand 1966; 88:1-69.

20. Rydell N. Biomechanics of the hip joint. Clin Orthop 1973;92:6-15.

21. Paul JP. Forces at the human hip joint [Doctoral dissertation]. Chicago, IL: University of Chicago, 1967.

22. Seireg A, Arvikar RJ. The prediction of muscular load sharing and joint forces at the lower extremities during walking. J Biomech 1975;8:89-102.

23. Crowninshield RD, Johnston RC, Andrews JG, Brand
RA. A biomechanical investigation of the human hip. J Biomech 1978;2:75-85.

24. Németh G. Hip load moments and muscular activity during lifting. Scand J Rehabil Med 1984;16:103-11.

25. Ericsson M, Bratt è, Nisell R, Németh $G$, Ekholm J. Load moments about the hip and knee joints during ergometer cycling. Scand J Rehabil Med 1986;18:1-8.

26. Mantel N, Haenszel W. Statistical aspects of analysis of data from retrospective studies of disease. J Natl Cancer Inst 1959;22:719-49.

27. Miettinen OS. Estimability and estimation in casereferent studies. Am J Epidemiol 1976;103:226- 35.

Received for publication: 10 September 199 